\title{
Prezervarea Splinei Într-Un Caz de Chist Splenic Voluminos
}

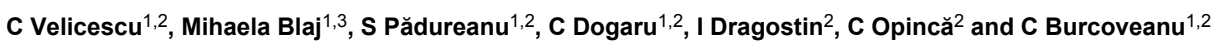 \\ ${ }^{1}$ Departamentul de chirurgie, Universitatea de Medicină și Farmacie Gr. "T. Popa", Iași, Romania \\ ${ }^{2}$ Clinica a IV a Chirurgie, Spitalul "Sf. Spiridon", Iași, Romania \\ ${ }^{3}$ Clinica A.T.I. Spitalul "Sf. Spiridon", Iași, Romania
}

*Corresponding author: Cristian Velicescu, MD, 4th Surgical Unit, "St. Spiridon” Hospital lași, Bd. Independenței, No 1, 700111 , lași, Romania, Tel: +40 (0) 232 232 24 08 22; E-mail: cristianvelicescu@yahoo.com

Received date: 19 October 2013, Accepted date: 30 December 2013, Published date: 15 May 2014

Copyright: (C) 2014 Velicescu C, et al. This is an open-access article distributed under the terms of the Creative Commons Attribution License, which permits unrestricted use, distribution, and reproduction in any medium, provided the original author(s) and source are credited.

\begin{abstract}
Splenic cysts are uncommon, not frequently encountered in surgical practice. Generally, they are considered to be either parasitic or non-parasitic. We report the case of a young woman who presented with pain in the left upper abdomen quadrant and nausea. Ultrasonography and CT scan revealed a giant cystic lesion arising from the splenic hilum compressing the stomach and pancreas. At laparotomy a huge cyst was found which was affecting also the splenic vein and artery. Through a meticulous surgical technique it was possible to preserve the spleen in this particular case. Cystectomy with spleen preservation is the treatment of choice for spleen cystic lesions, especially in young patients, due to its immunologic functions.
\end{abstract}

Keywords: Splenic Cysts; Spleen Preservation Surgery

\section{Introducere}

Chisturile splenice neparazitare sunt boli rare, dar care, odată cu utilizarea pe scară largă a ecografiei abdominale, au început să fie mai frecvent diagnosticate. Cel mai frecvent sunt asimptomatice și diagnosticul este de regulă incidental în cursul unei examinări ecografice "de rutină". Totuși unii pacienți pot prezenta dureri abdominale nesistematizate în hipocondrul stâng [1].

Chisturile splenice sunt mult mai frecvente decât leziunile solide; chisturile "adevărate" trebuie să fie diferențiate de pseudochisturile de pancreas și de degenerare chistică în urma contuziei splenice sau a infarctului splenic.

Chisturile pot fi congenitale (chisturi epidermoide), infecțioase (abces sau chist hidatic) sau neoplazice (limfangiome sau angiom $\mathrm{cu}$ necroză tumorală). În funcței de etiologie, chisturile splenice reprezintă o indicație de splenectomie (totală sau parțială); cu toate acestea la pacienții tineri se preferă prezervarea splinei pentru a limita expunerea pacienților la infecții severe [2-5].

\section{Prezentare Caz}

Pacienta G.G. de 23 ani, din mediul rural, studentă, se internează pentru simptomatologie nespecifică: dureri în hipocondrul şi flancul stâng mai ales în timpul efortului fizic, tulburări dispeptice. Pacienta nu prezintă antecedente heredo-colaterale sau patologice semnificative.

Examenul clinic decelează în hipocondrul stâng o formațiune tumorală dură, moderat dureroasă la palpare, care pare a aparține de splină. Probele biologice sunt în limite normale. Examenul ecografic evidențiază o formațiune chistică de $30 \times 20 \mathrm{~cm}$ situată în hilul splinei fără limită de demarcație de parenchimul splenic, care amprentează corpul gastric și coada pancreasului și comprimă vena şi artera splenică.
Examenul Computer Tomografic (CT) confirmă prezența unei formațiuni tumorale, rotunde, bine delimitate, de aspect chistic, de peste $20 \mathrm{~cm}$ diametru cu perete de $4 \mathrm{~mm}$ grosime și cu o calcificare de $4 \times 5 \mathrm{~cm}$; tumora este localizată la nivelul hilului splenic venind în contact cu marea curbură gastrică, corpul și coada pancreasului (Figure 1).

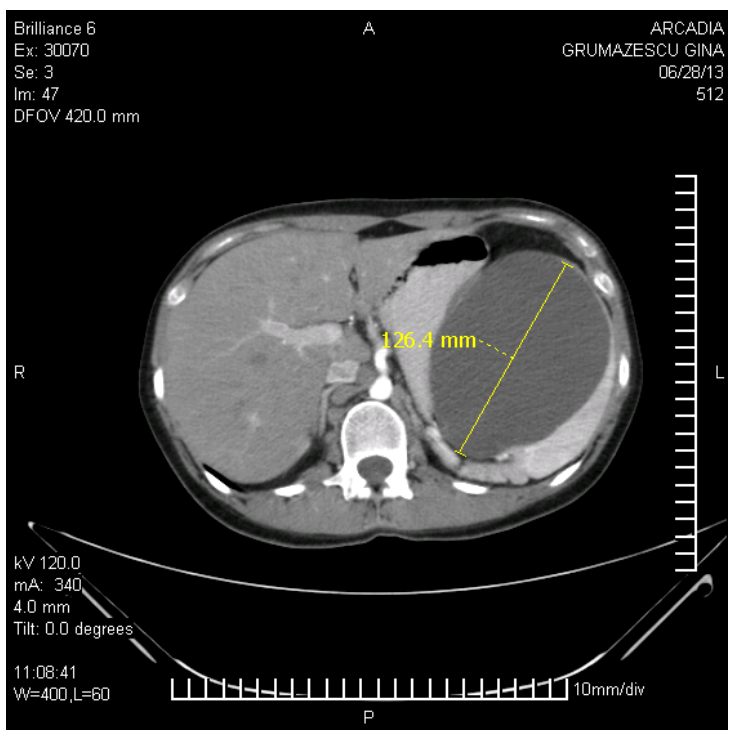

Figure 1: Examen CT cu substanţă de contrast - formaţiune chistică voluminoasă în hilul splinei.

S-a intervenit chirurgical sub anestezie generală; s-a practicat o incizie în "S" cu pătrunderea în cavitatea peritoneală. După secțiunea ligamentului gastro-colic se expune în un chist splenic gigant (cca 20 $\mathrm{cm}$ ) situat în hilul splenic, cu o zonă de calcificare parietală de $4 \times 5 \mathrm{~cm}$, fără a se putea vizualiza inițial parenchimul splenic. Aspectul 
Citation: Velicescu C, Blaj M, Padureanu S, Dogaru C, Dragostin I. Prezervarea Splinei Într-Un Caz de Chist Splenic Voluminos. Journal of Surgery [Jurnalul de Chirurgie] 2014; 10(1): 93-95. doi: 10.7438/1584-9341-10-1-19

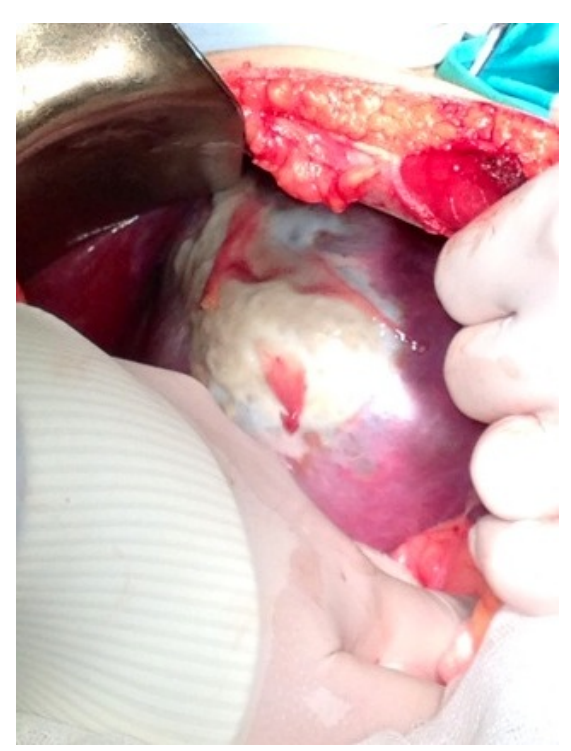

Figure 2: Aspect intraoperator - formațiune chistică splenică voluminoasă ce prezintă o calcificare parietală de $4 \times 5 \mathrm{~cm}$.

macroscopic este dificil de diferențiat de un chist hidatic splenic (Figure 2).

După izolarea câmpului operator și mobilizarea completă a chistului, se pune în evidență parenchimul splenic de aspect macroscopic, normal. Se practică ablația chistului (chistectomie ideală) cu minim de țesut splenic ataşat chistului, hemostază atentă şi prezervarea vaselor splenice (Figures 3 and 4).

Evoluția postoperatorie este favorabilă, cu reluarea tranzitului intestinal şi a toleranței digestive; evaluarea ecografică de control la 72 ore postoperator, arată un parenchim splenic normal, cu flux prezent în vasele splenice.

Pacienta se externează la 5 zile postoperator și este dispensarizată periodic; la doi ani de la intervenție nu prezintă recidivă.

Examenul anatomo-patologic al peretelui chistului relevă prezența unui chist epidermoid, țesutul splenic adiacent având o structură normală.

\section{Discuții}

Chisturile splenice neparazitare sunt clasic împărțite în două categorii: chisturile primare, ce includ chisturile congenitale (epidermoide), hemangioamele chistice, limfangioame, chisturi dermoide, chisturi neoplazice, tapetate la interior de un strat celular epitelial/mezotelial, și chisturile secundare (pseudo-chisturi), ce se dezvoltă în parenchimul splenic posttraumatic sau postinfecțios, și care nu prezintă formal un strat celular bazal [1]. Există însă autori care împărtășesc altă opinie: toate chisturile neparazitare sunt de origine congenitală, iar traumatismul nu este un factor patogenic principal în apariția chistului [2].

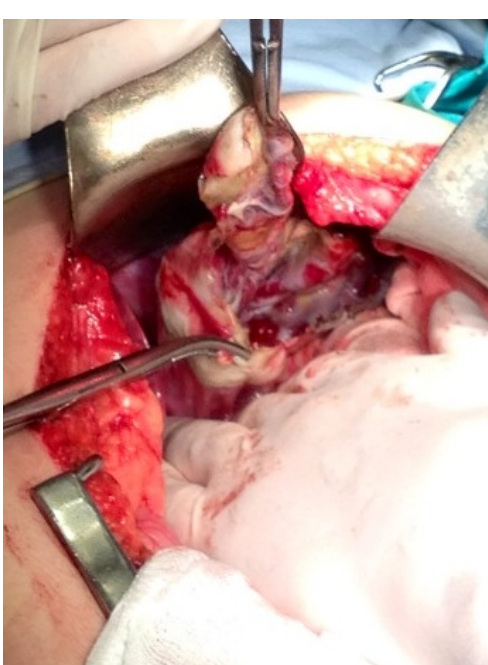

Figure 3: Chistectomia "ideală"; hemostază atentă la nivelul parenchimului splenic.

Chisturile splenice primare epidermoide sunt considerate de origine embrionară (disontogenetice), prezintă un vârf al frecvenței în copilărie și sunt o patologie mai des întâlnită în populația pediatrică [6], spre deosebire de chisturile secundare care totalizează peste $80 \%$ dintre leziunile chistice splenice neparazitare la adulți.

Dimensiunea medie a chisturilor splenice este de $13 \mathrm{~cm}, \mathrm{cu}$ limite foarte variabile $(4-20 \mathrm{~cm})$ [7]. Cei mai mulţi autori optează pentru intervenția chirurgicală dacă pacientul este simptomatic sau dacă dimensiunile chistului depășesc 4-5 cm, pentru restul leziunilor recomandându-se dispensarizarea clinică și imagistică [7]. Cu excepția leziunilor maligne, tratamentul chirurgical are drept obiectiv conservarea e parenchim splenic, mai ales la copii și tineri, pentru a evita complicațiile infecțioase $[7,8]$.

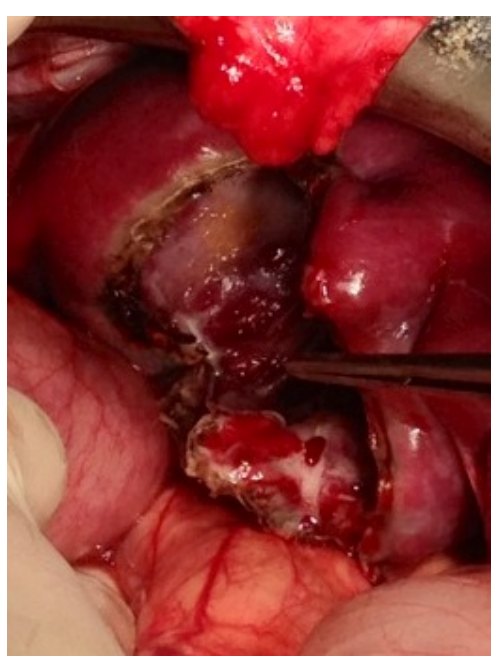

Figure 4: Aspect final după chistectomia "ideală"; de remarcat parenchimul splenic restant de aspect normal. 
Chisturile splenice simptomatice au indicație operatorie clară. Chistectomia parțială laparoscopică sau clasică (fenestrare) este o metodă sigură și eficientă, cu morbiditate minimă însă cu rată de recidivă semnificativă [9]. Recidivele pot fi de mici dimensiuni și asimptomatice, astfel încât nu necesită întotdeauna reintervenții. Unele recidive simptomatice pot beneficia de drenajul percutan ecoghidat și doar un număr limitat de cazuri necesită reintervenție chirurgicală. Tratamentul optim este considerat a fi chistectomia ideală, realizată pe care clasică sau minim invazivă, ce permite evitarea recidivelor $[10,11]$.

\section{Concluzii}

Chistectomia ideală reprezintă metoda optimă de tratament a chisturilor splenice primare (cu excepția neoplaziilor) având avantajul conservării parenchimului și funcțiilor splinei și permite evitarea morbidității generate de recidivele după chistectomiile parțiale.

\section{Conflict De Interese}

Autorii nu declară nici un conflict de interese.

\section{Bibliografie}

1. Hansen MB, Moller AC (2004) Splenic cysts. Surg Laparosc Endosc Percutan Tech 14: 316-322.

2. Vasilescu C (2005) [Laparoscopic splenectomy]. Chirurgia (Bucur) 100 595-598.
3. Tiron A, Vasilescu C (2008) [Role of the spleen in immunity. Immunologic consequences of splenectomy]. Chirurgia (Bucur) 103: 255-263.

4. Vasilescu C, Tomulescu V, Ciurea S, Popescu I (2001) [Laparoscopic splenectomy--lessons learned from a series of 40 cases. The advantages of the postero-lateral approach]. Chirurgia (Bucur) 96: 231-236.

5. McColl RJ, Hochman DJ, Sample C (2007) Laparoscopic management of splenic cysts: marsupialization, cavity lining with surgicel and omentopexy to prevent recurrence. Surg Laparosc Endosc Percutan Tech 17: 455-458

6. Gumbs AA, Bouhanna P, Bar-Zakai B, Briennon X, Gayet B (2008) Laparoscopic partial splenectomy using radiofrequency ablation. J Laparoendosc Adv Surg Tech A 18: 611-613.

7. Fisher JC, Gurung B, Cowles RA (2008) Recurrence after laparoscopic excision of nonparasitic splenic cysts. J Pediatr Surg 43: 1644-1648.

8. Kaiser MM, Fischer F, Wessel LM (2008) [The laparoscopic spleenpreserving approach to splenic cysts: advantages and limitations]. Zentralbl Chir 133: 142-147.

9. Tomulescu V, Stanciulea O, Balescu I, et al. First year experience of robotic-assisted laparoscopic surgery with 153 cases in a general surgery department: indications, technique and results. Chirurgia (Bucur.). 2009; 104(2): 141-150.

10. LuncÄf S, BouraÅŸ G, Dumitru L (2005) [Laparoscopic splenectomy for epithelial cyst of the spleen]. Rev Med Chir Soc Med Nat Iasi 109: 548-555.

11. Tudor S, Tiron A, Bobocea A, Popa M, SgarburÄf O, et al. (2009) [Nonparasitic splenic cysts--therapeutic solutions]. Chirurgia (Bucur) 104: 425-429. 